\title{
DESAIN KOMUNIKASI VISUAL SEBAGAI MEDIA PENUNJANG INFORMASI PADA EVENT RAKER XII PERGURUAN TINGGI RAHARJA
}

\author{
Lusyani Sunarya ${ }^{1}$ \\ Devy Rositarini ${ }^{2}$ \\ Riska Andriyanti ${ }^{3}$ \\ Alumni Universitas Islam Syekh Yusuf Tangerang ${ }^{1}$, STMIK Raharja Jurusan Teknik Informatika ${ }^{2,3}$ \\ Jl. Maulana Yusuf No. 10, Babakan, Tangerang ${ }^{1}$, Jl. Jendral Sudirman No. 40, Modernland, Tangerang ${ }^{2,3}$ \\ Email:lusyani.sunarya@raharja.info ${ }^{1)}$,devy@raharja.info ${ }^{2)}$, andriyanti@raharja.info ${ }^{3)}$
}

\begin{abstract}
ABSTRAK
Event adalah media komunikasi yang merupakan jembatan untuk meyampaikan suatu maksud atau tujuan dari pemilik event kepada target tertentu. Pada era ini event banyak diselenggarakan sebagai media promosi ataupun informasi. Perguruan Tinggi Raharja adalah lembaga yang bergerak dalam bidang pendidikan berbasis komputer dalam orientasinya. Setiap tahunnya Perguruan Tinggi Raharja selalu mengadakan event yang diadakan secara rutin sesuai dengan jadwal kalender kegiatan akademik yaitu RAKER XII. Dalam sebuah event, Desain Komunikasi Visual merupakan salah satu kebutuhan pokok sebagai sebuah alat penyampaian informasi dari sebuah event. Pengadaan event yang berlangsung biasanya membutuhkan berbagai bentuk media informasi dengan pesan yang up to date dan jelas, serta membutuhkan nuansa desain yang baru setiap tahunnya. Unsur-unsur tersebut sebagai media penyampaian informasi yang dibutuhkan sebuah event seperti memperkenalkan sebuah event sesuai dengan misi yang diharapkan. Media informasi yang digunakan pada event RAKER XII berupa Banner Family Gathering Raker XII, Banner Raker XII, Banner Raker XII (Keunggulan), Spanduk Raker XII, Spanduk Tema Raker, Spanduk Selamat Datang Raker XII, Pin Peserta dan Peninjau Raker XII, Umbul-umbul abawah RAKER, dan Cover Buku Renstra. Melalui perancangan Desain Raker XII ini diharapkan akan mendukung serta mensukseskan event Raker XII tahun 2015 pada Perguruan Tinggi Raharja, serta meningkatkan image Perguruan Tinggi Raharja agar dapat lebih dikenal masyarakat luas.
\end{abstract}

Kata Kunci : Desain Komunikasi Visual, Media Event, Media Informasi

\begin{abstract}
Event is a communication media is a bridge to present the intent or purpose of the event to a specific target. In this era, many held as a media event promotion or information. Perguruan tinggi raharja is an institution that specializes in computer-based education in their orientation. The university annually hosts Prog event held on a regular basis in accordance with the schedule of the academic calendar of events that is RAKER XII. In an event, Visual Communication Design is one of the basic needs as a means of delivering information from an event. Procurement event held usually requires various forms of media with messages that are up to date and clear, and it requires a new design nuances each year. Elements such as the media information needed an event such as the introduction of an event in accordance with the expected mission. Media information that is used in the form of event RSKER Banner Family Gathering XII Meeting XII Meeting XII Banner, Banner Raker XII (Excellence), XII Meeting banners, Banner Theme Raker, Banner Welcome Raker XII, Pin Joint and Reconnaissance Raker XII, banners bottom RAKER, Cover Book RENSTRA. Through design Design XII Meeting is expected as well as the success of the event will support the XII Meeting on Perguruan Tinggi Raharja, and improve the image of Perguruan Tinggi Raharja in order to be better known Prog wide community.
\end{abstract}

Keywords: Visual Communication Design, Media Event, Media Information 


\section{PENDAHULUAN}

Desain Komunikasi Visual merupakan salah satu kebutuhan pokok dalam sebuah event. Menyesuaikan dengan perkembangan saat ini gaya desain sangat berhubungan dengan memberikan unsurunsur hirarki dalam sebuah alat penyampaian infomasi dari sebuah event. Unsur-unsur tersebut sebagai media penyampaian informasi yang dibutuhkan sebuah event seperti memperkenalkan sebuah event sesuai dengan misi yang diharapkan. Bauran komunikasi pemasaran merupakan penggabungan dari lima model komunikasi dalam pemasaran, yaitu advertising, promosi penjualan (sales promotion), public relation, personal selling, dan direct selling. Sedangkan event dan exhibition merupakan bagian dari bauran media komunikasi pemasaran yang dikembangkan oleh bagian informasi.

Perguruan Tinggi Raharja adalah salah satu Perguruan Tinggi yang aktif di Tangerang. Perguruan Tinggi Raharja mempertahankan keberadaannya dalam ranah pendidikan dan tidak pernah berhenti untuk mengembangkannya. Perguruan Tinggi Raharja adalah sebuah lembaga pendidikan yang bergerak dibidang teknologi informasi, karena itu Perguruan Tinggi Raharja harus dapat meningkatkan kemajuan dunia pendidikan dalam memfasilitasi sistem pendukung informasi yang semakin meningkat.

$$
\text { Untuk dapat melaksanakan }
$$

kebijakan manajemen kampus, dalam mengakomodir

isu yang berkembang sekarang dan dimasa yang akan datang, seluruh program Kerja Manajemen yang ditetapkan pada Rapat Kerja tahunan (RAKER) pelaksanaanya dikerjakan oleh masing-masing Divisi berdasarkan persetujuan Pimpinan Perguruan Tinggi Raharja. Landasan pelaksanaan tugasnya senantiasa searah dengan Visi, Misi dan Tujuan yang tertuang dalam buku panduan tugas dan ditetapkan dalam Rapat Kerja tahunan Kampus yang sebut RENSTRA Manajemen Perguruan Tinggi Raharja.
Rencana Kerja Kampus adalah bagian dari Rencana Kerja Jangka Menengah (RKJM) Tahun 2013 - 2018, yang telah ditetapkan pada rapat kerja ke IV Tahun Akademik 2007 - 2008 dan harus dilaporkan pencapaian targetnya kepada Yayasan minimal satu tahun satu kali atau melalui Rapat Kerja tahunan Kampus Perguruan Tinggi Raharja pada akhir tahun.

Pada akhir tahun 2015 ini, Perguruan Tinggi Raharja akan melaksanakan event RAKER XII, yang akan dilaksanakan di Perguruan Tinggi Raharja. Untuk itu Perguruan Tinggi Raharja membutuhkan media komunikasi visual sebagai penunjang event RAKER XII tahun 2015. Komunikasi dalam kegiatan penunjang event RAKER XII membutuhkan media seperti banner, spanduk, cover buku, umbul-umbul, dan pin. Dengan adanya media tersebut diharapkan dapat mendukung keberhasilan dari sebuah event khususnya RAKER XII Perguruan Tinggi Raharja, agar dalam penyampaian informasi menjadi lebih baik dari yang diharapkan.

\section{PERMASALAHAN}

Setiap tahunnya Perguruan tinggi Raharja selalu mengadakan event yang diadakan secara rutin sesuai dengan jadwal kalender kegiatan akademik. Untuk itu Perguruan Tinggi Raharja, selalu berusaha menyampaikan informasi yang up to date mengenai penyelenggaraan event yang berlangsung kepada audience, yaitu seluruh peserta Raker XII dan Tamu Undangan. Pengadaan event yang berlangsung biasanya membutuhkan berbagai bentuk media informasi dengan pesan yang up to date dan jelas, serta membutuhkan nuansa desain yang baru setiap tahunnya, agar audience yang melihat tidak merasa bosan dan tertarik untuk mengetahui informasi mengenai event yang akan berlangsung. 


\section{LITERATURE REVIEW}

1. Penelitian yang dilakukan oleh Andry Budie Laksana, dan R. Eka Rizkiantono, SSn, MDs (2013) dari Fakultas Teknik Sipil dan Perencanaan, Institut Teknologi Sepuluh Nopember (ITS) yang berjudul "PERANCANGAN PROMOSI EVENT PEKAN BUDAYA DAN PARIWISATA KEDIRI 2013" Kabupaten Kediri sebagai salah satu destinasi pariwisata di Jawa Timur yang memiliki beragam potensi kepariwisataan, seni budaya, dan produk-produk unggulan daerah yang berkualitas, berdaya saing, dan layak jual serta diminati oleh wisatawan, dalam rangka pengembangan promosi kepariwisataan dan meningkat-kan atau menguatkan citra destinasi pariwisata Kabupaten Kediri pada peta wisata nasional, maka Pemerintah Kabupaten Kediri menyelenggarakan event "Pekan Budaya dan Pariwisata Kabupaten Kediri Tahun 2012" dengan tema "Kediri Bumi Panji Merajut Nusantara" pada bulan Juni 2012 di Kawasan Simpang Lima Gumul Kediri. Dalam upaya mensukseskan program "Sadar Wisata", Pemerintah Daerah kabupaten Kediri yang menyadari akan pentingnya sebuah event promotion untuk mewujudkan visi dan misi mereka sebagai daerah destinasi pariwisata dan bisnis, berharap dengan adanya event Pekan Budaya dan Pariwisata ini akan mendukung ambisi dan mengeksploitasi potensi mereka, akhirnya menyusun perencanaan untuk melakukan perancangan event Pekan Budaya dan Pariwisata kabupaten Kediri 2013.

2. Penelitian yang dilakukan oleh Victor Adiluhung Abednego dan Sayatman, S.Sn, M.Si (2014) dari Fakultas Teknik Sipil dan Perencanaan, Institut Teknologi Sepuluh Nopember (ITS) yang berjudul "PERANCANGAN
EVENT SUPPORT CRAFT AND FASHION 2014 DENGAN KONSEP EXCLUSIVE HERITAGE" Dunia UKM di Indonesia (termasuk UKM bidang craft dan fashion) saat ini menuju perkembangan yang baik, produk-produknya pun semakin berkualitas. Craft and Fashion sebagai event pameran UKM terbesar di Indonesia Timur memfasilitasi kebutuhan UKM akan sebuah acara yang dapat mempromosikan produk dan bidang usaha mereka. Namun tujuan tersebut tidak diimbangi dengan strategi media dan visual yang terintegrasi, hal ini menyebabkan awareness masyarakat terhadap event ini menurun tiap tahunnya. Untuk menyelesaikan problematika tersebut maka dibentuklah perancangan ini, perancangan ini sendiri melingkupi studi dan perancangan identitas event, pemeilihan dan perancangan media dan implementasi media-media pendukung event tersebut. Dengan mengusung konsep Exclusive Heritage desain ini diharapkan dapat diterima dengan mudah oleh target segmen sehingga event ini dapat berjalan sesuai konsep yang diinginkan dan pengunjung pun dapat tertarik untuk datang ke event ini. Melalui konsep Exclusive Heritage ini produk-produk UKM dapat ditampilkan secara elegan, glamour dan terkesan mewah tanpa harus meninggalkan unsur tradisional dari produk-produk tersebut.

3. Penelitian yang dilakukan oleh Surya Aditama dan Sayatman, S.Sn, M.Si (2014) dari Fakultas Teknik Sipil dan Perencanaan, Institut Teknologi Sepuluh Nopember (ITS) yang berjudul "PERANCANGAN PROMOSI EVENT MAJAPAHIT TRAVEL FAIR 2013" Majapahit Travel Fair adalah pameran pariwisata tahunan yang diselenggarakan oleh Dinas Pariwisata dan Budaya Jawa Timur. Event berupa pameran pariwisata tahunan ini memiliki tujuan untuk mempromosikan dan 
mengembangkan pariwisata, melestarikan nilai-nilai budaya daerah, serta menciptakan peluang bisnis dalam sektor pariwisata. Untuk membantu memaksimalkan tujuan event, Dinas Pariwisata Jawa Timur melalui buku laporan Majapahit Travel Fair 2011 menyebutkan bahwa kualitas promosi event ini harus terus ditingkatkan. Hal tersebut juga ditunjang dengan hasil penelitian penulis terhadap data primer dan sekunder yang menghasilkan kesimpulan bahwa Majapahit Travel Fair cukup dikenal oleh insan pariwisata, namun belum dikenal secara lebih luas, dan belum memiliki konsep komunikasi serta strategi promosi yang maksimal.

4. Penelitian yang dilakukan oleh Rurin Niken Hardyanti, Muh.Bahruddin dan Sigit Prayitno Yosep (2014) dari STMIK STIKOM Surabaya yang berjudul "PERANCANGAN MEDIA PROMOSI EVENT PUTRI LBC PADA LONDON BEAUTY CENTRE SEBAGAI UPAYA MENINGKATKAN BRAND LOYALTY' Putri LBC merupakan salah satu acara yang pernah diselenggarakan oleh keindahan Centre London. London kecantikan Centre lebih dikenal sebagai LBC merupakan salah satu klinik kecantikan terkemuka yang telah berdiri selama 16 tahun dan memiliki 46 cabang di seluruh di Indonesia. Putri LBC adalah kontes kecantikan yang ditujukan untuk wanita, terutama remaja. Acara ini merupakan sarana untuk membangun hubungan yang baik dengan pelanggan secara langsung. Namun sejauh ini, Putri LBC belum kegiatan promosi yang dirancang dengan baik dan hanya mengandalkan promosi dari mulut untuk menginformasikan acara untuk penonton. hal ini menyebabkan kurang pelanggan tahu tentang acara dan Putri LBC tidak mempengaruhi peningkatan pelanggan yang mengunjungi klinik LBC. Masalahnya adalah bahwa LBC adalah klinik yang telah mengalami belum pengunjung menurun secara bertahap karena klinik kecantikan semakin banyak bermunculan, terutama di Surabaya, dibutuhkan beberapa upaya untuk mempertahankan loyalitas pelanggan, salah satunya adalah untuk merancang sebuah media promosi yang tepat untuk Putri LBC yang dapat memberikan informasi kepada masyarakat dalam rangka meningkatkan klinik kecantikan loyalitas merek London Beauty Centre.

5. Penelitian yang dilakukan oleh Resita Lifenia (2013) dari Fakultas Seni dan Desain Universitas Kristen Petra, Surabaya yang berjudul "PERANCANGAN MEDIA PROMOSI TRIWULAN EVENT ARTOTEL SURABAYA" Perancangan Komunikasi Visual ini bertujuan untuk memperkenalkan Triwulan Event sehingga dengan adanya promosi yang efektif maka diharapkan akan membuat masyarakat datang berkunjung ke Artotel untuk melihat Triwulan Event yang berada di lobby Artotel. Promosi yang efektif guna untuk menjangkau target market agar promosi yang ingin disampaikan melalui beberapa media antara lain: poster, X-banner , kalender, brosur, gantungan kunci, dan placemat akan tersampaikan dengan baik. Masa promosi akan dilakukan selama 3 bulan melai bulan Agustus - Oktober 2013. Diharapkan dari masa promosi Triwulan Event tersebut akan memberikan jawaban terhadap pencapaian tujuan promosi di atas secara tepat dan efektif.

\section{LANDASAN TEORI}

\section{Pengertian Informasi}

Menurut Maimunah (2012: 284)

"Informasi adalah data yang telah diolah menjadi sebuah bentuk yang lebih berarti 
bagi penerimanya, dan bermanfaat dalam mengambil sebuah keputusan".

\section{Pengertian Media}

Menurut Maimunah, dkk (2012:284) "Media adalah sarana untuk menyimpan pesan atau informasi kepada publik dengan menggunakan berbagai unsur komunikasi grafis seperti teks atau gambar atau foto".

Menurut Rahardja, dkk (2011:133) "Media adalah saluran penyimpanan pesan komersial kepada khalayak sasaran atau dapat dikatakan salah satu komunikasi periklanan yang dilakukan melalui saluran media tertentu, seperti televisi, surat kabar, majalah, radio, internet, buku profil, media luar ruangan, iklan transit dan direct email".

\section{Pengertian Event}

Menurut Noor (2010:7) definisi dari event adalah suatu kegiatan yang diselenggarakan untuk memperingati halhal penting sepanjang hidup manusia, baik secara individu atau kelompok yang terikat secara adat, budaya, tradisi, dan agama yang diselenggarakan untuk tujuan tertentu serta melibatkan lingkungan masyarakat yang diselenggarakan pada waktu tertentu.

Event adalah media komunikasi yang merupakan jembatan untuk meyampaikan suatu maksud atau tujuan dari pemilik (client) kepada target, rangkaian kegiatan yang memberikan pengalaman secara langsung dan nyata.

\section{Rapat Kerja (RAKER)}

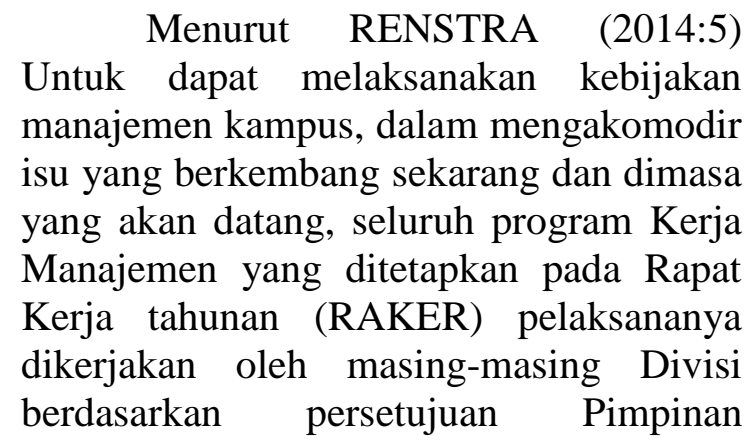

Perguruan Tinggi Raharja.Landasan pelaksanaan tugasnyasenantiasa searah dengan Visi, Misi dan Tujuan yang tertuang dalam buku panduan tugas dan ditetapkan dalam Rapat Kerja tahunan Kampus yang sebut RENSTRA Manajemen Perguruan Tinggi Raharja.

Rencana Kerja Kampus adalah bagian dari Rencana Kerja Jangka Menengah (RKJM) Tahun 2013 - 2018, yang telah ditetapkan pada rapat kerja ke IV Tahun Akademik 2007 - 2008 dan harus dilaporkan pencapaian targetnya kepada Yayasan minimal satu tahun satu kali atau melalui Rapat Kerja tahunan Kampus Perguruan Tinggi Raharja pada akhir tahun.

\section{Pengertian Desain Komunikasi Visual}

Menurut Supriyono (2010:10) Desain grafis belakangan lebih sering disebut "desain komunikasi visual" (DKV) karena memiliki peran mengkomunikasikan pesan atau informasi kepada pembaca dengan berbagai kekuatan visual, seperti tipografi, ilustrasi warna, garis, layout dan sebagainya dengan bantuan teknologi”.

\section{PEMBAHASAN}

\section{Perencanaan Media}

Media yang digunakan sebagai media penunjang informasi tentang event RAKER XII adalah media spanduk luar ruangan digunakan sebagai petunjuk lokasi penyelenggaraan event dan ucapan selamat datang kepada audience, sedangkan spanduk dan banner dalam ruangan digunakan sebagai informasi event yang berlangsung. Media umbul-umbul digunakan sebagai dekorasi dan petunjuk lokasi penyelenggaraan event. Media pin digunakan sebagai tanda untuk peninjau dan peserta. Media cover buku digunakan sebagai informasi utama dalam buku Renstra Manajemen Perguruan Tinggi Raharja Tahun 2015-2016 yang akan 
diberikan pada peserta dan peninjau Raker XII Perguruan Tinggi Raharja.

\section{Konsep Kreatif}

Konsep kreatif yang akan dituangkan kedalam media-media penunjang event RAKER XII dengan menampilkan visual yang lebih mengarah kepada teknologi sesuai dengan Perguruan Tinggi Raharja sebagai kampus IT yang berbasis komputer. Setiap desain juga disertai dengan Logo Perguruan Tinggi Raharja, ISO dan KAN (Komite Akreditasi Nasional), serta terdapat teks yang menarik dan sudah disesuaikan penempatannya untuk menginformasikan isi dari setiap desain, selain itu warna yang di tampilkan secara mayoritas yaitu warna hijau sebagai warna identitas green campus Perguruan Tinggi Raharja dan warna pendukung lainnya seperti warna kuning dan orange sehingga warna yang ditampilkan terkesan cerah, menarik dan sesuai dengan citra Perguruan Tinggi Raharja.

\section{Penulisan Naskah}

Pada rancangan media event RAKER XII pada Perguruan Tinggi Rahraja terdapat unsur-unsur komunikasi grafis seperti teks (tulisan), ilustrasi (foto atau image), warna dan elemen desain. Salah satunya adalah naskah atau teks (tulisan) sebagai headline ataupun subheadline bodycopy yang diperlukan dalam perancangan agar penyampain pesan dapat mudah dimengerti dan tepat sasaran, teks digunakan sebagai judul (headline), sub judul, naskah (body copy), logo (logo type) pada desain media event Raker XII ini penulisan naskah diperlukan untuk menginformasikan sebuah event yang diselenggarakan Perguruan Tinggi Raharja.

\section{Pengarahan Visual}

Warna yang dipilih adalah hijau muda, hijau tua, kuning, oranye, merah dan putih. Dengan dominan warna hijau yang mencirikan identitas Perguruan Tinggi Raharja.

Jenis huruf yang dipakai dalam perancangan diantaranya menggunakan beberapa jenis huruf yang karakternya sesuai dengan karakter huruf yang selama ini dipergunakan, yaitu: Machine $B T$, Times New Rowman, Times New Roman Bold, Bookman Old Style Bold, Arial Black Italic, Geometric 706BT Black condensed, Dutch801BT BoldItalic, Geometric 231BT HeavyC, Myraid Pro, Arial Black, AbadiMT Consonded, Adobe Garamond Pro, Myriad Roman, Myraid Pro Bold, Grouch BT, Arial.

Gaya tampilan visual secara grafis ditampilkan dengan nuansa hijau, kuning dan oranye sehingga terlihat terang dan menarik dan sesuai dengan identitas yaitu green campus Perguruan Tinggi Raharja, dimaksudkan agar audience dapat lebih mudah mengetahui pesan media yang disampaikan.

\section{Proses Desain}

1. Layout Kasar

Layout kasar adalah penerapan elemen-elemen desain media yang nantinya akan dipergunakan dalam perancangan media komunikasi visual yang disertai acuan standarisasi pada desain yang akan dibuat, umumnya dibuat dengan tampilan hitam putih, dibuat dengan coretan atau sketsa dengan menggunakan pensil gambar. Layout kasar diperlukan, sebagai panduan pada saat proses desain dengan menggunakan aplikasi komputer. Berikut adalah gambar layout kasar proses perancangan media event RAKER XII. 


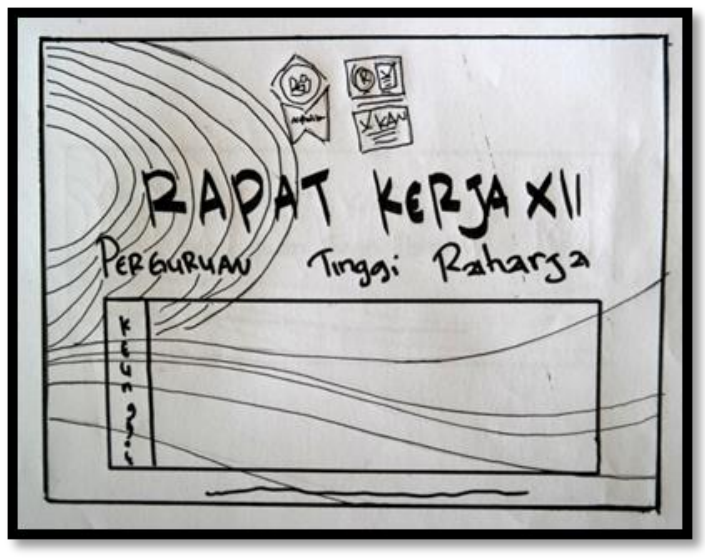

Gambar.1. Layout Kasar Banner RAKER

Pada gambar 1 yaitu menggambarkan layout kasar banner RAKER XII yang berisikan informasi tentang keunggulan Perguruan Tinggi Raharja yang akan di pasang di pintu masuk Grand Max Theater (GMT).

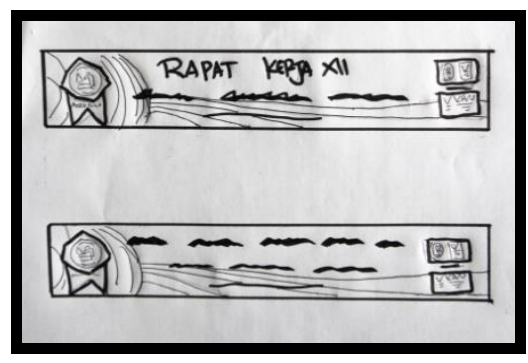

Gambar. 2. Spanduk RAKER XII

Pada gambar 2 yaitu menggambarkan layout kasar spanduk acara RAKER XII yang berisikan informasi tentang event yang berlangsung yang akan di pasang di panggung Grand Max Theater (GMT) dan sepanduk selamat datang peserta RAKER XII yang di pasang pada pintu masuk Perguruan Tinggi Raharja.

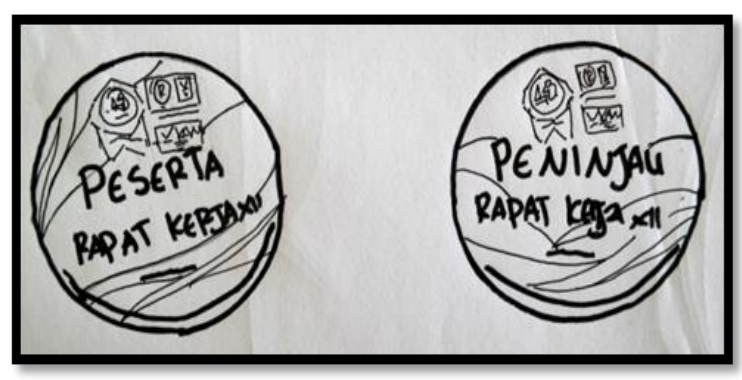

Gambar. 3. Layout Kasar Pin

Pada gambar 3 yaitu menggambarkan layout kasar pin peserta dan peninjau RAKER XII yang akan digunakan oleh peserta dan peninjau RAKER XII sebgai tanda keikutsertaan acara tersebut.

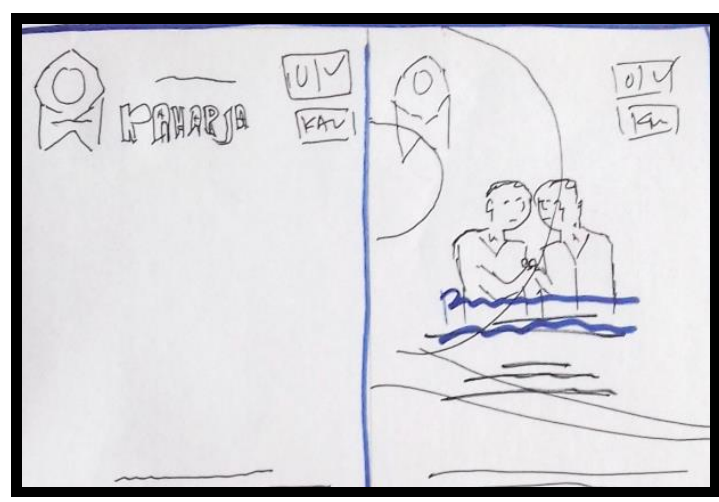

Gambar. 4. Layout Kasar Memo RAKER XII

Pada gambar 4 yaitu menggambarkan layout kasar memo RAKR XII yang akan dibagikan kepada seluruh peserta dan tamu undangan yang hadir pada event tersebut

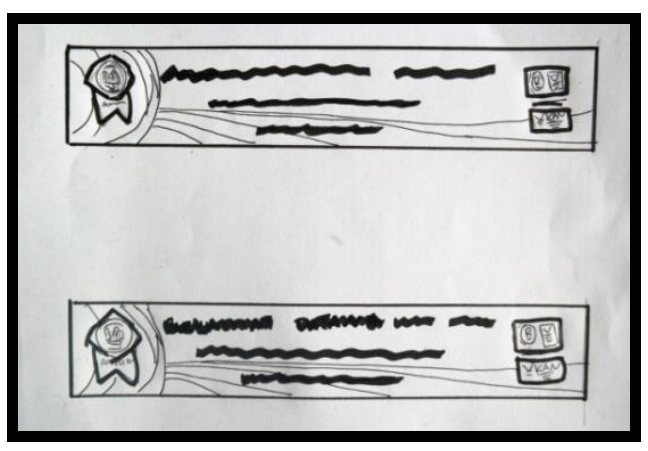

Gambar. 5. Layout Kasar spanduk moto dan tema

Pada gambar 5 yaitu menggambarkan layout kasar spanduk motto dan tema RAKER XII yang berisikan informasi tentang, motto manajemen : $3 \mathrm{~T}$ (Terencana, Terukur, Terealisasi), 3E (Efisien, Efektif. Elegan). Tema : Rapat Kerja Manajemen XII Tahun 2015 Penguatan 10 Prinsip Dasar Manajemen Kampus Perguruan Tinggi Raharja, yang akan di pasang di dalam Grand Max Theater (GMT). 


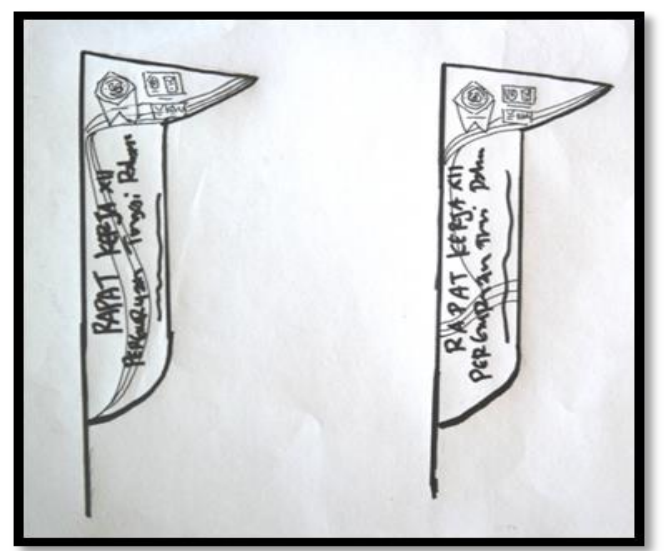

Gambar. 6. Layout Kasar Umbul-umbul

Pada gambar 6 yaitu menggambarkan layout kasar umbul-umbul bawah RAKER XII yang berisikan informasi tentang event yang berlangsung dan sebagai dekorasi pendukung event yang akan di pasang pada Perguruan Tinggi Raharja.

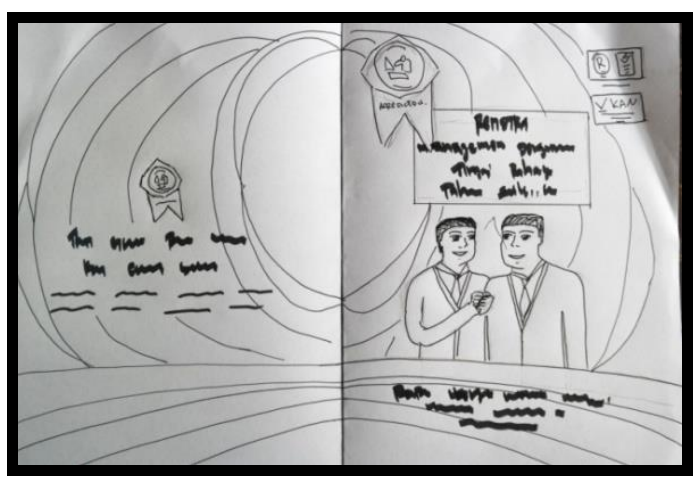

Gambar. 7. Layout Kasar Cover Renstra 2015

Pada gambar 7 yaitu menggambarkan layout kasar cover RENSTRA Manajemen Perguruan Tinggi Raharja tahun 20152016 yang akan dibagikan kepada seluruh peserta dan tamu undangan yang hadir pada event tersebut.

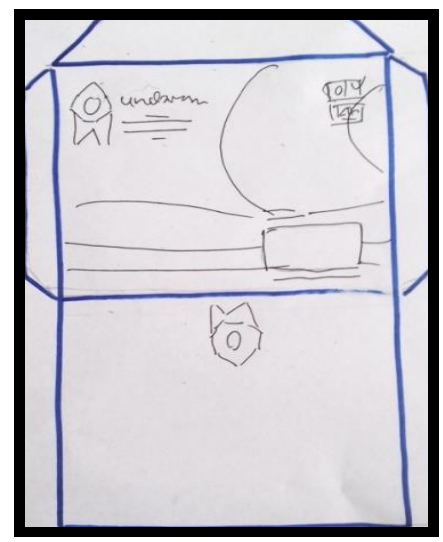

Gambar. 8. Layout Kasar Amplop RAKER XII
Pada gambar 8 yaitu menggambarkan layout kasar amplop undangan RAKER XII yang akan dibagikan kepada seluruh peserta dan tamu undangan yang hadir pada event tersebut.

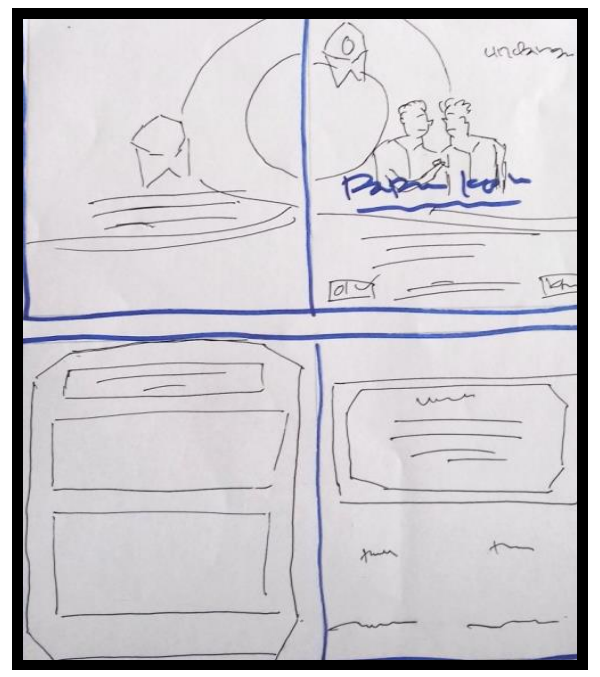

Gambar. 9. Layout Kasar cover isi undangan RAKER XII

Pada gambar 9 yaitu menggambarkan layout kasar isi undangan RAKER XII yang akan dibagikan kepada seluruh peserta dan tamu undangan yang hadir pada event tersebut.

\section{Layout Kompherensif}

Layout kompherensif adalah proses desain yang sudah memasuki tahap komputerisasi dan pewarnaan, namun tahap ini belum selesai seutuhnya, karena masih harus mengalami proses revisi. berikut adalah layout kompherensif media event RAKER XII.

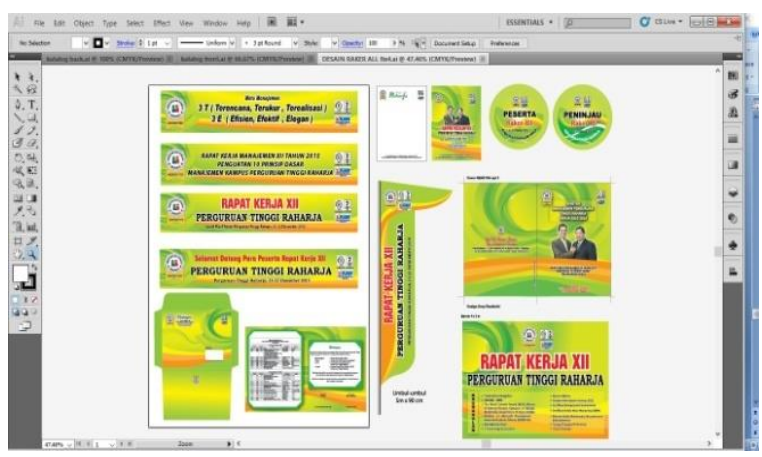

Gambar.10.

Layout Kompherensif RAKER 2015 
3. Final Artwork

Hasil akhir dari layout komprehensif yang telah diperbaiki, dimana tahap ini merupakan hasil akhir atau finishing, yang kemudian dapat digunakan untuk acuan saat proses produksi. Berikut tahapan proses akhir dari perancangan media event RAKER XII.

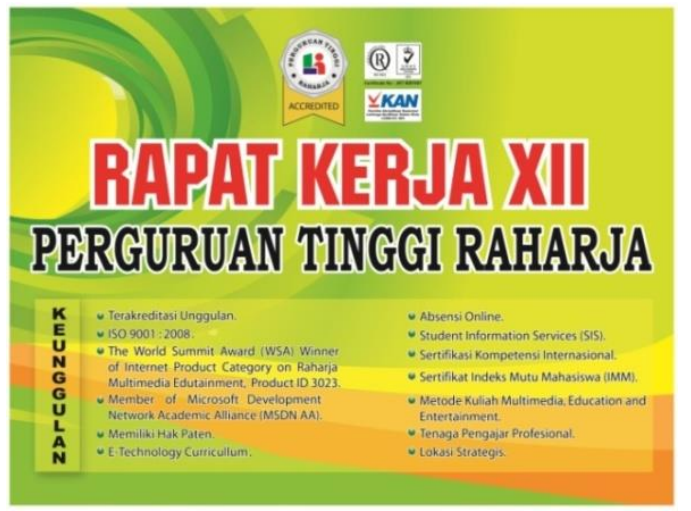

Gambar.11. Final Art Work Banner RAKER XII

Gambar 11 diatas menggambarkan hasil akhir yang telah finish berupa banner RAKER XII ukuran 4x3 m dengan bahan flexi china.

Spanduk RAKER GMT $6 \times 1,15 \mathrm{~m}$

RAPAT KERJA XII

Spanduk Selamat Datang RAKER $6 \times 1,15 \mathrm{~m}$

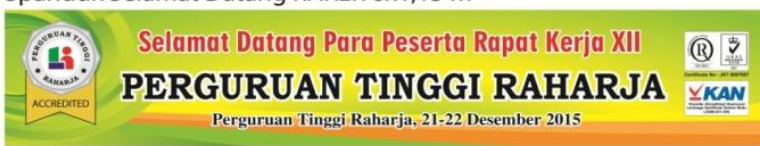

Gambar.12. Final Art Work Spanduk acara dan spanduk selamat datang RAKER XII

Gambar 12 di atas menggambarkan hasil akhir berupa Spanduk acara dan spanduk selamat datang RAKER XII dengan ukuran $6 \times 1,15 \mathrm{~m}$ dan menggunakan bahan flexi china.

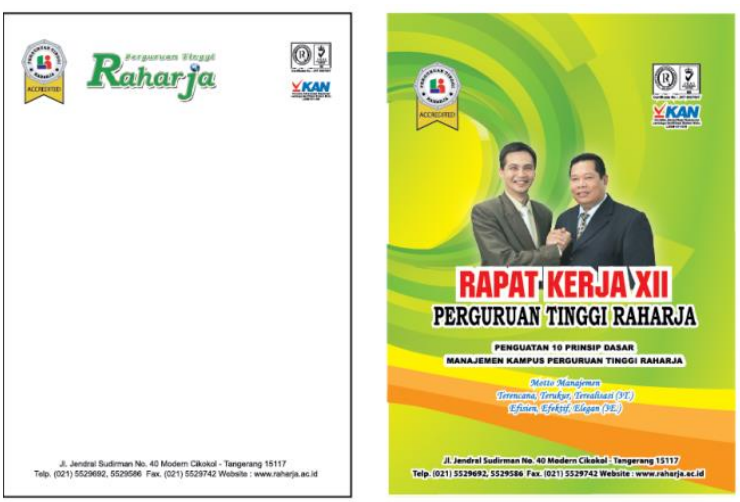

Gambar.13. Final Art Work memo RAKER XII

Gambar 13 di atas menggambarkan hasil akhir berupa memo RAKER XII dengan ukran A4 21x29,7 cm menggunakan bahan inkjet paper.

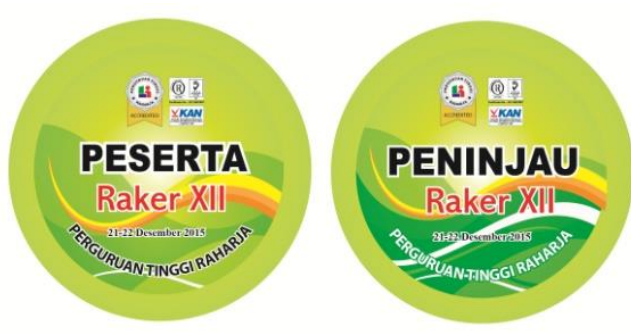

Gambar.14. Final Art Work PIN

Gambar 14 di atas menggambarkan hasil akhir berupa PIN RAKER XII ukuran $5,8 \mathrm{~cm}$ menggunakan bahan peniti, kaleng, plastik, inkjet paper.

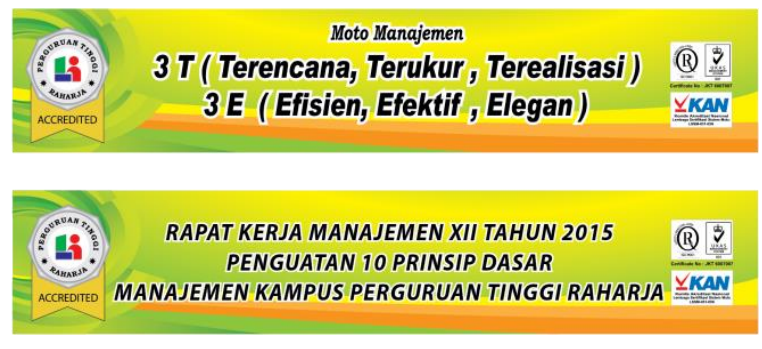

Gambar.15. Final Art Work Spanduk Motto dan
Tema

Gambar 15 di atas menggambarkan hasil akhir berupa spanduk Motto dan Tema RAKER XII ukuran 6x1,15 m dan menggunakan bahan flexi china. 


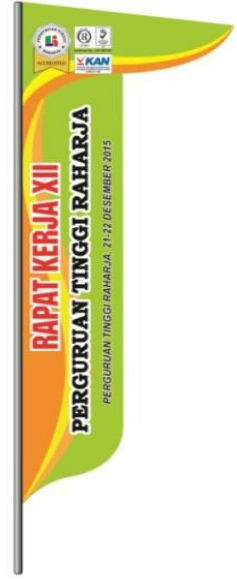

Gambar.16. Final Art Work Umbul-umbul

Gambar 16 di atas menggambarkan hasil akhir berupa umbul-umbul RAKER XII ukuran $5 \mathrm{~m} \quad \mathrm{x} 90 \mathrm{~cm}$ dengan menggunakan bahan kain tetoron.

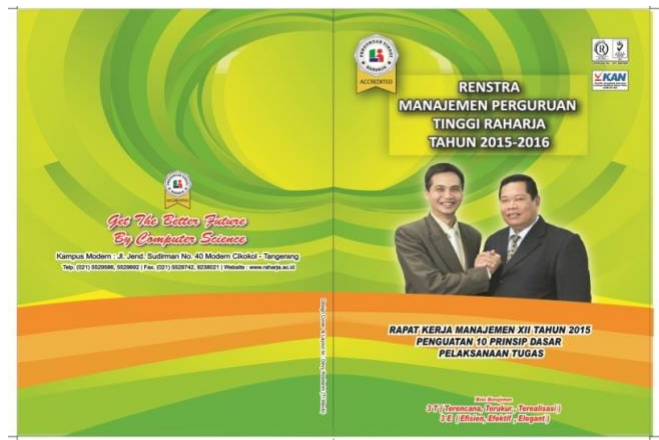

Gambar.17. Final Art Work Cover Buku Renstra

Gambar 17 di atas menggambarkan hasil akhir berupa Cover Buku RENSTRA 2015 ukuran A4 21x29,7 cm menggunakan bahan art karton.
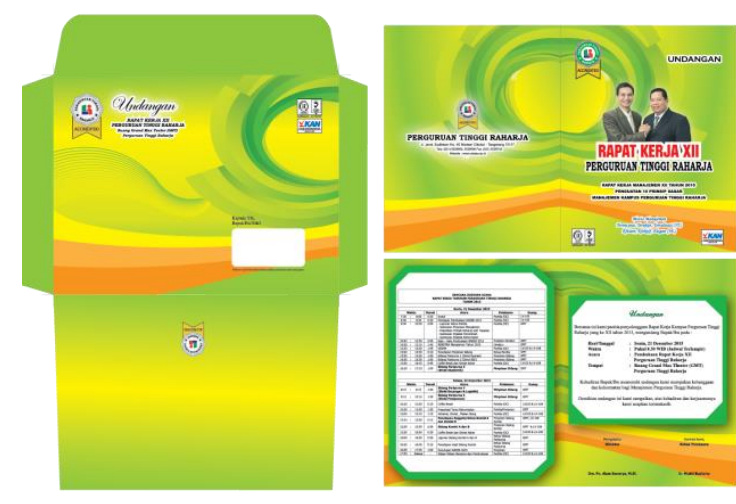

Gambar.18. Final Art Work Cover Buku Renstra
Gambar 18 di atas menggambarkan hasil akhir berupa amplop dan undangan RAKER XII ukuran Amplop 22x17 cm \& Undangan 21,5x16,5 $\mathrm{cm}$ menggunakan bahan art karton.

\section{KESIMPULAN}

Media komunikasi visual dalam sebuah kegiatan event sangat penting dan berguna dalam memperkenalkan citra/image suatu instansi, serta untuk mensukseskan event yang berlangsung. Pada event RAKER XII kali ini media yang digunakan adalah spanduk, banner, cover buku, pin dan umbul-umbul. Media ini di pilih karena dapat menunjang informasi event yang berlangsung. Merancang media yang mempunyai nilai daya tarik dengan Media Komunikasi Visual yang sesuai dengan pencitraan Perguruan Tinggi Raharja dan desain yang memiliki corak, komposisi elemen media yang sesuai dengan perkembangan atau trend yang ada pada saat ini, desain yang fresh, menarik, informasinya up to date dan jelas, sehingga dapat dijadikan daya tarik audience untuk mendapatkan informasi mengenai event RAKER XII.

\section{DAFTAR PUSTAKA}

[1] Abednego, Victor Adiluhun, Sayatman. 2014. Perancangan Event Support Craft and Fashion 2014 Dengan Konsep Exclusive Heritage. Surabaya: Institut Teknologi Sepuluh Nopember.

[2] Aditama, Surya, Sayatman. 2014. Perancangan Promosi Event Majapahit Travel Fair 2013. Surabaya: Institut Teknologi Sepuluh Nopember.

[3] Budie Laksana, Andry, R. Eka Rizkiantono. 2013. Perancangan Promosi Event Pekan Budaya dan Pariwisata Kediri 2013. Surabaya: Institut Teknologi Sepuluh Nopember. 
[4] Hardyanti, Rurin Niken, Muh.Bahruddin, Sigit Prayitno Yosep. 2014. Perancangan Media Promosi Event Putri LBC Pada London Beauty Centre Sebagai Upaya Meningkatkan Brand Loyality. Surabaya: STMIK STIKOM

[5] Lifenia, Resita. 2013. Perancangan Media Promosi Triwulan Event Artotel Surabaya. Surabaya: Universitas Kristen Petra.

[6] Maimunah, Lusyani Sunarya, Nina Larasati. 2012. Media Company Profile Sebagai Sarana Penunjang Informasi dan Promosi, Journal CCIT Vol.5 No.3. Tangerang: Perguruan Tinggi Raharja.

[7] Noor, Any. 2010. Managemen Event. Bandung: Alfabeta

[8] RENSTRA. 2014. Manajemen Perguruan Tinggi Raharja, Tangerang: Perguruan Tinggi Raharja

[9] Rahardja, Untung, Dewi Immaniar Destrianti dan Reni Mulyani. 2011. Audio Visual As One of The Teaching Resources On Learning, Journal CCIT Vol.5 No.2, Tangerang: Perguruan Tinggi Raharja.

[10] Supriyono, Rakhmat. 2010. Desain Komunikasi Visual Teori dan Aplikasi, Yogyakarta : Andi. 